\title{
Associations among Physician Advice, Physical Activity, and Socio-demographic Groups in Older Spanish Adults*
}

\author{
María Martín Rodríguez, ${ }^{1}$ Jesús Martínez del Castillo, ${ }^{1}$ José Antonio Serrano Sánchez, ${ }^{2}$ \\ José Emilio Jiménez-Beatty Navarro, ${ }^{3}$ José Antonio Santacruz, ${ }^{3}$ and Antonio Rivero Herráiz ${ }^{1}$
}

\begin{abstract}
RÉSUMÉ
Cette étude a examiné la relation entre l'avis médicale pour s'engager dans ld'activité physique avec, le type de demande d'activité physique et les variables démographiques. Une étude transversale a été élaborécréé. Un questionnaire avec des items sur l'avis médicale, le niveau de demande pour l'activité physique, et les variables démographiques a été complété par une échantillon national de personnes âgées en Espagne ( $\mathrm{N}=933, \mathrm{M}=74,1$, range de 65 à 93), sélectionnées de manière aléatoire à plusieurs étapes. Les personnes âgées actifs actives physiquement ont plus souvent reçu des avis médicale médicaux à la pratiquepour s'engager dans ld'activité physique que les personnes non activefs. Il existe une relation significative entre l'avis médicale et le type de demande $(\mathrm{p}<.01)$ et l'âge $(\mathrm{p}<.05)$. Cependant, aucune relation n'a été trouvée déterminée entre l'avis médicale d'activité physique et le sexe, la classe sociale, ou le revenu. Les médécins peuvent effectivement favoriserencourager l'activité physique chez les adultes âgés sédentaires par des conseils d'activité physiqueavec un résultat efficace. Donc, les autorités sanitaires devraient promouvoir encourager aux médécins de conseiller à leurs patients plus âgés de s'engager dans l'activité physiqueles conseils médicaux de l'activité physique à leurs patients âgés.
\end{abstract}

\begin{abstract}
This study examined the relationship between medical advice to engage in physical activity with type of demand required by physical activity and demographic variables. A cross-sectional study was developed, featuring a questionnaire on physicians' advice, and type of demand. The questionnaire was completed by a probability and nationwide sample of older adults in Spain ( $n=933, M=74.1$, range 65-93), randomly selected using multistage sampling. More physically active older adults have, more often than the less active, received physicians' advice to engage in physical activity. There is a significant relationship between medical advice and type of demand $(p<.01)$ and age $(p<.05)$. However, no relationship was found between physician medical advice and gender, social class, or income. Physicians can effectively promote physical activity among sedentary older adults through appropriate advice. Consequently, health authorities should promote physicians' advising older patients to pursue physical activity.
\end{abstract}

1 Polytechnic University of Madrid, Spain

2 Las Palmas University, Spain

3 Alcalá University, Spain

* We thank the research participants for their cooperation. We received support for research, and/or authorship of this article, through work supported by the Ministry of Education and Science (Spain) and European Regional Development Fund (ERDF) European funds (National Research Plan I+D+i DEP2005-00161-C03); aid to support research and development lines of research groups at the Polytechnic University of Madrid (UPM05-C-11 203); and Aid for Research Projects University of Alcalá.

Manuscript received: / manuscrit reçu : 28/02/11

Manuscript accepted: / manuscrit accepté : 06/01/12

Mots clés : personnes âgées espagnoles, activité physique, avis médicale, étude transversale

Keywords: Spanish older adults, physical activity, physician advice, cross-sectional study

Correspondence and requests for offprints should be sent to / La correspondance et les demandes de tirés-à-part doivent être adressées à:

Jesús Martínez del Castillo, Ph.D.

Department of Physical Activity and Social Sciences

7 Martín Fierro

Polytechnic University of Madrid

Madrid, Spain 28040

(jesus.martinezd@upm.es) 
Physical inactivity, independently of other risk factors, is associated with a higher rate of mortality and morbidity in middle-age and older adults (Carlsson, Andersson, Wolk, \& Ahlbom, 2006; Franco et al., 2005; Martinson, Crain, Pronk, O'Connor \& Maciosek, 2003). Promoting physical activity is a public health priority for all ages (World Health Organization, 2004) and particularly for older adults, since the majority are inactive or insufficiently active (Florindo et al., 2009; Kruger, Ham, \& Sanker, 2008; Zhao, Ford, Li, \& Balluz, 2011).

Older adults are the group that is growing most rapidly in developed societies (Desai, Zhang, \& Hennessy, 1999; Nkomo et al., 2006; Roudsari, Ebel, Corso, Molinari, \& Koepsell, 2005). In the context of the present study's focus (Spain), the annual increase in the older adult population segment is about 2.5 per cent versus 0.83 per cent for the whole population (Instituto de Mayores y Servicios Sociales, 2009). It has been estimated that the number of older Spanish adults ( $\geq 65$ years old) will increase up to 30 per cent of the whole population in 2050 (vs. 16.8\% at present). The most prevalent forms of morbidity in this group include arthritis and rheumatism $(53 \%)$, hypertension $(51.9 \%)$, chronic low back pain (30.2\%), dyslipidemia (30\%), depression (20.9\%), type 2 diabetes (17.9\%), and osteoporosis (14.7\%) (Instituto de Mayores y Servicios Sociales, 2009). Public health expenditures among older adults is also growing, representing about 44 per cent of the total health service budget and 48.5 per cent of the pharmacological budget (VaquéRafart \& San José-Laporte, 2002). Similar figures have been reported in the United Kingdom (Taylor et al., 2004).

One strategy to promote regular physical activity is physician advice (Shephard, 2000; Pfeiffer, Clay, \& Conatser, 2001; Nied \& Franklin, 2002). That is, physicians could counsel their patients to adopt and maintain regular physical activity in order to retain functionality and quality of life (Balde, Figueras, Hawking, \& Miller, 2003). However, the prevalence of older adults' receiving physician advice for physical activity appears to be low (Balde et al., 2003; Jiménez-Beatty Navarro, Graupera, Martínez del Castillo, Martín, \& Campos, 2007; Mills et al., 2001; Rhodes et al., 1999; Stephens \& Craig, 1990).

Physicians have specific training that enables them to consider the cost-benefit relationship of their advice and prescriptions. Because it is well known that older adults have a greater risk of falling (Agrawal, Carey, Della Santina, Schubert, \& Minor, 2009; Kemmlert \& Lundholm, 2001) and suffering cardiovascular events than younger adults (Burt et al., 1995; Saez, Suarez, Blanco, \& Gabriel, 1998), for example, it is important that physicians consider previous medical conditions when advising older adults to partake in physical activity. Guidelines for prescribing physical activity to older adults are available from the American College of Sports Medicine (Nelson et al., 2007). In addition, algorithms to predict the risk of falling in older adults have been developed by the American Geriatric Society (Panel on Prevention of Falls in Older Persons, 2010). Nevertheless, according to Shephard (2000) and Hirvensalo, Heikkinen, Lintunen, and Rantanen (2005), many physicians adopt a cautious approach to giving physical-activity advice, and there remains a need to increase practitioners' understanding of the importance of physical activity for their patients. Nied and Franklin (2002), for example, have suggested that it is imperative that physicians take the lead in motivating older sedentary patients to adopt an active lifestyle. However, a U.K. study showed that the percentage of physicians who practice physical activity or sports was less than the average of the entire population (Halvorson, 2009). The implication is that physicians who themselves are not active are thus less likely to prescribe that their patients be active.

Pfeiffer et al. (2001) conducted an intervention study to determine whether, when added to verbal advice to be more active, a written prescription for older adults increased their physical activity. The authors compared the physical activity response between two groups: (a) those who received advice only, versus (b) those who received advice plus a written prescription. Both groups showed a significant increase in physical activity without differences due to advice modalities.

The association between receiving physician advice and the type of physical activity in older adults have been assessed by Balde et al. (2003). In a retrospective survey, with results based on patient recall, they found that 61.6 per cent reported receiving advice about physical activity from their physician during the year previous to the survey. Balde et al. (2003) also found that older adults who had received physician advice promoting physical activity showed no differences in light and sitting activities compared with those who did not receive physical activity-related advice. However, those older adults who received physician advice promoting physical activity performed more moderate physical activities than those whose physicians did not prescribe physical activity. Physician advice for physical activity can be integrated into a socio-cognitive framework to promote physical activity in older adults (Maly, Costigan, \& Olney, 2007; Umstattd, Wilcox, Saunders, Watkins, \& Dowda, 2008).

A review of the literature on the prevalence and the influence of physician advice revealed some limitations with regard to sampling. Most of the studies drew on nonprobability samples, particularly convenience sampling, and were not representative of the populations of older adults from which they were drawn. As a result, the conclusions lack external validity. Moreover, none of the previous studies had examined the relationship 
with the types of demand for physical activity (Martínez del Castillo, Rodríguez, Jiménez-Beatty, \& Graupera, 2005), a variable that classifies individuals based on their level of involvement and their interest in engaging in some physical activity at present. The categories of demand are as follows: (a) established demand (ED), individuals who engage in habitual leisure-time physical activity; (b) latent demand (LD), individuals who do not engage in habitual leisure-time physical activity, but would like to do at least one activity and are interested in becoming active; and (c) absence of demand (AD), individuals who do not engage in a leisure-time physical activity and furthermore are not interested in doing so. A retrospective survey, with results based on patient recall, with a random selection of the older adult participants in Madrid, Spain, $(n=630)$ showed moderate associations between receiving physician advice for physical activity and the types of demand (Jiménez-Beatty et al., 2007). The majority of older adults in the ED group (64\%) had received physician advice while this percentage was lower (57\% and 37\%) in the $\mathrm{LD}$ and $\mathrm{AD}$ groups respectively.

There are few studies, using a representative sample of a country's elderly population, that focus on the prevalence and association of physician advice with physical activity. It has been suggested that early old age is a critical period for promoting physical activity (Shaw \& Spokane, 2008), and different intervention strategies for groups with different socioeconomic status may be needed. However, there is a lack of studies showing potential socio-demographic differences (i.e., age, gender, income level) in physician advice for physical activity among older adults.

The aims of our study, the focus of this article, were to examine the following research questions with reference to a nationally representative sample of older Spanish adults:

1. What is the prevalence of medical advice for physical activity in the population of older adults and the different groups of demand by age, gender, social class, and income level?

2. Does a significant relationship exist between physician advice to engage in physical activity and the three groups of demand for physical activity (ED, LD, and AD) in old age?

3. Are there significant relationships between physician advice to engage in physical activity and the sociodemographic variables of age, gender, social class, and income level in old age?

\section{Methods}

Sampling

Our study, cross-sectional in design, was carried out in 2006 through face-to-face interviews with a random sample of 933 community-living older adults residing in Spain. Multistage probability sampling was used (Bryman, 2004). In stage 1, the sampling units were Spanish towns; there was a random selection of two towns for each of the following population sizes (number of residents): $<10,000 ; 10,001$ to 50,$000 ; 50,001$ to 100,000; and >100,001. The number of interviews in each town was proportional to the number of older adults. In stage 2, a random selection of 94 boroughs in each sampled town was performed. In stage 3, the sampling units were the randomly selected streets at the start of each interviewer's route.

Addresses were also randomly selected. In each home, we interviewed one person. If more than one person in a household was eligible, we interviewed the person who opened the door. When the person with the selected profile was not at home, a time for a second visit was established. The response rate was 73.2 per cent. For those interviews that could not be carried out, we applied a random procedure to select another home and participant with the same age, gender, and stratum profile. The overall result was that 933 older adults were interviewed in their own homes, and they answered the questionnaire adequately. The study was performed in accordance with the Helsinki Declaration of 1975, last modified in 2000, regarding the conduct of clinical research.

\section{Questionnaire and Measures}

The standardized and validated written questionnaire by Jiménez-Beatty et al. (2007) on physician advice and type of demand for physical activity was used. Briefly, the questionnaire had 34 items with two main components: physical activity and socio-demographic data. The physical activity component had 24 items including type, duration, frequency, physician advice, outcome expectations, motives and beliefs for physical activity, format of physical activity, cost, places, characteristics of places, perceived functional capacity, and preferences for physical activities. The questionnaire combined categorical scales for qualitative information with ordinal scales for assessed grade differences. For the present study, we collected selected data to measure socio-demographic characteristics and types of physical activity as follows.

Socio-demographic variables: Age in years was a continuous variable and gender a dichotomy $(1=$ male, $2=$ female). We assessed perceived social class by asking participants to self-rank on a 5-point scale from lower to higher social class. This subjective measure has shown better associations with several indicators of physical and mental health than more objective measures of socioeconomic position (Boyce, Brown, \& Moore, 2011; Liu et al., 2004; Ostrove, Adler, Kuppermann, \& 
Washington, 2000; Singh-Manoux, Adler, \& Marmot, 2003). For analytic purposes, social class was recoded into three levels $(1=$ upper $/$ upper-middle class, $2=$ middle class, 3 = lower-middle/lower class). Income level was assessed with regard to respondents' perceptions of having sufficient money to pay their basic bills (household, clothes, food, medical expenses) with three categorical levels ("sufficient income to pay my bills", "I deprive myself of necessary things", and "I need financial help to pay the bills"). In the analyses, income was recoded as a binary variable $(1=$ sufficient income, 2 = financial problems). The test-retest reliability of the social class and income measures, assessed four to six weeks later in a subsample of 89 participants, showed a Cramer's V correlation coefficient $\left(r_{\mathrm{v}}\right)$ of 0.89 and 0.85 respectively.

Physician advice for physical activity was defined as verbal or written messages provided by the physician, including recommendations, counseling, or written prescriptions to begin, maintain, or increase physical activity. It was assessed with a direct question and a dichotomous scale: "In the last year, has your physician given you advice to do any physical activities or play any sports?" The responses were coded as $1=$ yes or $2=$ no $\left(r_{\mathrm{v}}=0.91\right)$.

Type of demand for physical activity: This nominal variable had three categories as defined earlier: ED, LD, and $\mathrm{AD}$. To classify the respondents, we used the responses to two dichotomous questions. First, all respondents were asked if they currently engaged in any type of leisure, exercise, or sporting physical activity, such as walking, dancing, or other activities (excluding household chores) within a recreational setting. Participants were asked to report habitual physical activity, defined as doing 25-30 minutes daily at least 5 days of the week ( $1=$ yes, $2=$ no). If participants answered affirmatively, they were classified as ED; if they answered negatively, they were asked a follow-up question as to whether they wished to carry out any habitual leisure, exercise, or physical sports activity. Those who said "yes" were coded as LD, and those who said "no" as AD. Reliability for the first and second questions was acceptable $\left(r_{\mathrm{v}}=\right.$ 0.87 and $r_{\mathrm{v}}=0.83$ respectively). The output variable, namely type of demand, had an $r_{\mathrm{v}}=0.84$.

\section{Data Analysis}

Contingency table analysis was performed, including the value of Pearson chi-square and significance $(p<.05)$. We used the phi correlation coefficient to analyse the relationship among physician advice, the type of demand, and the socio-demographic variables. The software package we used for these analyses was IBM SPSS for Windows 15.0.

\section{Results}

\section{Sample Characteristics}

Over half $(54.7 \%)$ of the respondents were between 65 and 74 years of age, and the remainder $(45.3 \%)$ were 75 years of age or older (Mean \pm standard deviation $=$ $74.1 \pm 6.5$ years old, range: $65-93$ ) (see Table 1). Less than half $(46.9 \%)$ were men. With regard to perceived

Table 1: Prevalence of physician advice of physical activity by type of demand and demographic variables

\begin{tabular}{|c|c|c|c|c|c|c|}
\hline Variables and Categories & $n$ & $\%$ & \multicolumn{4}{|c|}{ Physician Advice ( $n=933$ ) } \\
\hline \multicolumn{7}{|l|}{ Type of demand } \\
\hline Established demand & 162 & 17.3 & 82 & 50.6 & 80 & 49.4 \\
\hline \multicolumn{7}{|l|}{ Age } \\
\hline $65<75$ years & 510 & 54.7 & 215 & 42.2 & 295 & 57.8 \\
\hline$\geq 75$ years & 423 & 45.3 & 149 & 35.2 & 274 & 64.8 \\
\hline \multicolumn{7}{|l|}{ Gender } \\
\hline Men & 438 & 46.9 & 171 & 39.0 & 267 & 61.0 \\
\hline Women & 495 & 53.1 & 193 & 38.9 & 302 & 61.1 \\
\hline \multicolumn{7}{|l|}{ Current income } \\
\hline Sufficient & 442 & 47.4 & 169 & 38.2 & 273 & 61.8 \\
\hline Has financial problems & 491 & 52.6 & 190 & 38.7 & 301 & 61.3 \\
\hline
\end{tabular}


social class, 8.9 per cent declared themselves to be upper or upper-middle class, 55.3 per cent as middle class, and 35.8 per cent as lower-middle or lower class. More than half of the older participants $(52.6 \%)$ reported living with financial problems whereas the remaining participants $(47.4 \%)$ reported having sufficient income.

\section{Physician Advice and Type of Demand}

In total, 39 per cent of the older adults surveyed reported having received medical advice for physical activity over the past year (see Table 1). Most (69.9\%) reported no interest in a habitual level of physical activity; only 17.3 per cent reported engaging in habitual physical activity. The relationship between receiving physician advice and the type of demand was low but significant $\left(\Phi=.18 ; \chi^{2} d f\right.$ [degree of freedom] 2, 29.44; $\left.p<.01\right)$. The proportion of older adults in the ED and LD groups who reported that they had received physician advice was similar ( $50.6 \%$ and $54.6 \%$ respectively), and higher than it was among those in the AD group (33.3\%).

\section{Physician Advice and Socio-demographic Variables}

A slightly higher proportion of older adults aged 65 through 74 reported receiving physician advice regarding physical activity at least once in the past year, compared with those aged 75 years and older $(42.2 \%$ vs. $35.2 \%)$, a relationship that was statistically significant $\left(\Phi=.07 ; \chi^{2} d f 1,4.49 ; p=<.05\right)$. However, there was no difference between males and females with respect to receiving physician advice regarding physical activity. Similarly, although some differences emerged when comparing the upper/upper-middle classes with the middle-middle and lower-middle/lower classes, the association was not statistically significant. With regard to income level, the same proportion of cases receiving physician advice for physical activity was found among people reporting sufficient income as among those with insufficient income.

\section{Discussion}

\section{Prevalence of Physician Advice for Physical Activity}

Approximately four out of ten older Spanish adults (39\%) reported receiving advice from their physician at least once in the past year to begin, maintain, or increase in physical activities. Access to medical services in Spain is universal. Less than one per cent $(0.6 \%)$ of the Spanish population does not have universal access; hence, almost all Spaniards are in a similar situation when it comes to accessing medical consultation and receiving physician advice.

The prevalence of medical advice being prescribed in Spain for physical activity appears rather low since more than two thirds of older adults report at least one chronic condition in which physical activity may lead to a preventive or therapeutic benefit (Instituto de Mayores y Servicios Sociales, 2009). Yet, the prevalence of perceived physician advice for physical activity in the present study is similar to that (41\%) observed earlier by Jiménez-Beatty et al. (2007) in Madrid. In contrast, the prevalence of physician advice for physical activities in older Spanish adults is lower than that observed in samples from other countries (above 56\%; e.g., Mills et al. [2001] with a sample from northern California, and Balde et al. [2003] with samples from U.S. cities).

These differences could reflect a lower awareness in Spain than in the United States and elsewhere about the importance of physician advice for physical activity. In those countries, physician advice is recognized as one of the strategies for promoting active lifestyles and health among older adults (Sheppard, Senior, Park, Mockenhaupt, \& Chodzko-Zajko, 2003). Further research could examine why a greater number of physicians do not give advice regarding physical activity to older people (Halvorson, 2009). For example, it remains unknown whether a physician's activity patterns or lifestyle could influence the provision of physical activity-related advice.

\section{Physician Advice and Type of Demand for Physical Activity}

Moderate but significant associations were found between receiving physician advice and the demand for physical activity. One out of every two older adults in the ED (50.6\%) and the LD (54.6\%) groups reported having received physician advice, compared with one out of three (33\%) in the AD group. This is in agreement with the population study from the Madrid area (Jiménez-Beatty et al., 2007). The association between physician advice for physical activity and the increase in the number of physically active older adults concurs with other studies (Balde et al., 2003; Mills et al., 2001). The present study leads us to suggest that physician advice could be associated with increased interest in physical activity (LD group) although the participants reported a low level of activity.

\section{Physician Advice and Socio-demographic Variables}

This is the first study to examine the prevalence of perceived physician advice in different demographic groups of older adults. Hence, the results cannot be compared with previous studies. It would be interesting if further studies were to examine socio-demographic differences in the provision and efficacy of physical activity-related advice.

In the present study, we did not find consistent differences among the socio-demographic groups examined. 
Only age showed a low and significant association with participants' having received physician advice regarding physical activity at least once. Glasgow, Eakin, Fisher, Bacak, \& Brownson (2001) found that the likelihood of receiving physician advice for physical activity was lower among adults aged $\geq 65$ in comparison to those aged $45-64$. In our study, the oldest group ( $\geq 75$ years old) reported being less likely to receive such advice than those under age 75 . This could be related to the number of physician visits; however, the literature suggests that there is no direct relationship between the frequency of visits and the prevalence of exposure to physician advice for physical activity in older adults. Among Spanish older adults, the oldest group ( $\geq 75$ years) has the highest frequency of visits to physicians (Instituto de Mayores y Servicios Sociales, 2009), but contrary to what might be expected, in the present study they had the lowest prevalence of physicians' advice for physical activity. A study could be conducted to determine whether this age-related difference in medical advice for physical activity could be due to the greater incapacity of older adults or to physicians' beliefs about physical activity in older patients. It has been noted (Musha, 2008; Shephard, 2000) that some physicians advise against physical activity for older patients with health problems, suggesting overprotective counseling towards older adults.

With respect to gender, there was no difference between groups in their exposure to physician advice. A slightly higher proportion of older adults in upper/uppermiddle social class levels received physician advice promoting physical activity compared with those in the lower-middle/lower classes. Referring to the income level, the proportion receiving physician advice was found to be similar among those with sufficient income and those without. It appears that physicians advise physical activity to their patients independently of their income level.

Finally, the present study does have certain limitations. A cross-sectional study does not allow for determining causal relationships which may be achieved with longitudinal or intervention studies. Nevertheless, a cross-sectional design is the best option for use with large populations to explore associations that might justify subsequent intervention studies to determine the efficacy of physician advice to promote physical activity among older adults.

Participant recall is another limitation. In the present study, we used the past year as the period to report having received physician advice specifically for physical activity. Differences in the quality of recall have been reported among female cardiac patients: inactive and obese women were more likely to recall limited verbal advice about diet and physical activity (Rushford et al.,
2007). However, recall may depend on the type of information provided. Information about medication, exercise, and smoking cessation are reportedly better recalled than other lifestyle advice such as gardening and driving (Rushford et al., 2007). Our study did not focus on the type of physician-provided information but on whether or not participants had received some type of advice regarding physical activity. This approach minimized the loss of recalled information.

Of additional interest to our study because it had a bearing on participant recall is a randomized cluster trial conducted with Spanish adults in primary care and specifically designed to measure the impact of advice and prescriptions for physical activity in previously inactive adults (Grandes et al., 2009). That trial showed a moderate improvement of physical activity in the "advised" and "prescription" intervention groups aged 50-80, compared with the corresponding age control group without advice or prescription, despite all of them being previously inactive. This suggests that inactive adults aged $50-80$ become active as a result of physician advice rather than from the quality of the adults' recall of their previously inactive condition. Our study concurs with others reporting that recalling no exerciserelated advice was most common among people who were sedentary (Hirvensalo et al., 2005). Further research would be necessary to determine if there are differences in recalled physical activity-related advice between active and inactive subjects, with conclusive methodology such as longitudinal and intervention designs applied to determine the direction of the relationship.

In conclusion, this study confirms the findings of previous regional studies about the positive influence on older adults of their receiving physician advice to increase participation in an active lifestyle. This means there is a greater prevalence of physician advice for physical activity in older adults who are already active or who would like to be so (ED and LD groups) than in inactive older adults (AD group). Health authorities from different countries should implement programs to encourage a greater number of physicians to recommend physical activity to their older patients. Therefore it is proposed as a strategy to reduce the number of sedentary older adults that health authorities from different countries should implement programs to encourage a greater number of physicians to recommend physical activity to their older patients.

\section{References}

Agrawal, Y., Carey, J.P., Della Santina, C.C., Schubert, M.C., \& Minor, L.B. (2009). Disorders of balance and vestibular function in US adults: Data from the National Health and Nutrition Examination Survey, 2001-2004. Archives of Internal Medicine, 169, 938-944. 
Balde, A., Figueras, J., Hawking, D.A., \& Miller, J.R. (2003). Physician advice to the elderly about physical activity. Journal of Aging and Physical Activity, 11(1), 90-97.

Boyce, C.J., Brown, G.D., \& Moore, S.C. (2011). Money and happiness: Rank of income, not income, affects life satisfaction. Psychological Science, 2, 471-475.

Burt, V.L., Cutler, J.A., Higgins, M., Horan, M.J., Labarthe, D., Whelton, P., et al. (1995). Trends in the prevalence, awareness, treatment, and control of hypertension in the adult US population. Data from the health examination surveys, 1960 to 1991. Hypertension, 26, 60-69.

Bryman, A. (2004). Social research methods. New York: Oxford University Press.

Carlsson, S., Andersson, T., Wolk, A., \& Ahlbom, A. (2006). Low physical activity and mortality in women: Baseline lifestyle and health as alternative explanations. Scandinavian Journal of Public Health, 34(5), 480-487.

Desai, M.M., Zhang, P., \& Hennessy, C.H. (1999). Surveillance for morbidity and mortality among older adults - United States, 1995-1996. Morbidity and Mortality Weekly Report, CDC, 48(8), 7-25.

Florindo, A.A., Guimaraes, V.V., Cesar, C.L., Barros, M.B., Alves, M.C., \& Goldbaum, M. (2009). Epidemiology of leisure, transportation, occupational, and household physical activity: Prevalence and associated factors. Journal of Physical Activity and Health, 6(5), 625-632.

Franco, O.H., de Laet, C., Peeters, A., Jonker, J., Mackenbach, J., \& Nusselder, W. (2005). Effects of physical activity on life expectancy with cardiovascular disease. Archives of Internal Medicine, 165(20), 2355-2360.

Glasgow, R.E., Eakin, E.G., Fisher, E.B., Bacak, S.J., \& Brownson, R.C. (2001). Physician advice and support for physical activity: Results from a national survey. American Journal of Preventive Medicine, 21, 189-196.

Grandes, G., Sanchez, A., Sanchez-Pinilla, R.O., Torcal, J., Montoya, I., Lizarraga, K., et al. (2009). Effectiveness of physical activity advice and prescription by physicians in routine primary care: A cluster randomized trial. Archives of Internal Medicine, 169(7), 694-701.

Halvorson, R. (2009). Doctors don't heed own advice. IDEA Fitness Journal, 6(4), 13.

Hirvensalo, M., Heikkinen, E., Lintunen, T., \& Rantanen, T. (2005). Recommendations for and warnings against physical activity given to older people by health care professionals. Preventive Medicine, 41(1), 342-347.

Instituto de Mayores y Servicios Sociales. (2009). Las personas mayores en España. Informe 2008 [Older persons in Spain. Report 2008]. Madrid, Spain: Ministerio de Sanidad y Política Social.

Jiménez-Beatty Navarro, J.E., Graupera, J.L., Martínez del Castillo, J., Martín, M., \& Campos, A. (2007). Motivational factors and physician advice for physical activity in older urban adults. Journal of Aging and Physical Activity, 15(3), 241-256.

Kemmlert, K., \& Lundholm, L. (2001). Slips, trips and falls in different work groups - with reference to age and from a preventive perspective. Applied Ergonomics, 32, 149-153.

Kruger, J., Ham, S.A., \& Sanker, S. (2008). Physical inactivity during leisure time among older adults - Behavioral Risk Factor Surveillance System, 2005. Journal of Aging and Physical Activity, 16(3), 280-291.

Liu, W.M., Ali, S.R., Soleck, G., Hopps, J., Dunston, K., \& Pickett, T. Jr. (2004). Using social class in counseling psychology research. Journal of Counseling Psychology, $51,3-18$.

Maly, M.R., Costigan, P.A., \& Olney, S.J. (2007). Self-efficacy mediates walking performance in older adults with knee osteoarthritis. Journal of Gerontology, 62(10), 1142-1146.

Martínez del Castillo, J., Rodríguez, M.L., Jiménez-Beatty, J.E., \& Graupera, J.L. (2005). Influencia de la educación física escolar en la práctica de actividad física en la vejez. [The physical education influence in primary school on the practice of physical activity in old age]. Motricidad. European Journal of Human Movement, 13, 71-86.

Martinson, B.C., Crain, A.L., Pronk, N.P., O'Connor, P.J., \& Maciosek, M.V. (2003). Changes in physical activity and short-term changes in health care charges: A prospective cohort study of older adults. Preventive Medicine, 37, 319-326.

Mills, K.M., Stewart, A.L., McLellan, B.Y., Verboncoeur, C.J., King, A.C., \& Brown, B.W. (2001). Evaluation of enrollment bias in a physical activity promotion program for seniors. Journal of Aging and Physical Activity, 9(4), 398-413.

Musha, H. (2008). Decision for allowing patients with heart disease to participate in sports. Japanese Journal of Clinical Sports Medicine, 16(2), 146-152.

Nelson, M.E., Rejeski, W.J., Blair, S.N., Duncan, P.W., Judge, J.O., King, A. C., et al. (2007). Physical activity and public health in older adults: Recommendation from the American College of Sports Medicine and the American Heart Association. Circulation, 116(9), 1094-1105.

Nied, R.J., \& Franklin, B. (2002). Promoting and prescribing exercise for the elderly. American Family Physician, 65(3), 419-426.

Nkomo, V.T., Gardin, J.M., Skelton, T.N., Gottdiener, J.S., Scott, C.G., \& Enriquez-Sarano, M. (2006). Burden of valvular heart diseases: A population-based study. Lancet, 368(9540), 1005-1011.

Ostrove, J.M., Adler, N.E., Kuppermann, M., \& Washington, A.E. (2000). Objective and subjective assessments of socioeconomic status and their relationship to self-rated health in an ethnically diverse sample of pregnant women. Health Psychology, 19, 613-618. 
Panel on Prevention of Falls in Older Persons. (2010). Summary of the Updated American Geriatrics Society/British Geriatrics Society clinical practice guideline for prevention of falls in older persons. Journal of American Geriatric Society, 59(1), 148-157.

Pfeiffer, B.A., Clay, S.W., \& Conatser, R.R. (2001). A green prescription study: does written exercise prescribed by a physician result in increased physical activity among older adults? Journal of Aging and Health, 13(4), 527-538.

Rhodes, R.E., Martin, A.D., Taunton, J.E., Rhodes, E.C., Donnelly, M., \& Elliot, J. (1999). Factors associated with exercise adherence among older adults: an individual perspective. Sports Medicine, 28(6), 397-411.

Roudsari, B.S., Ebel, B.E., Corso, P.S., Molinari, N.A., \& Koepsell, T.D. (2005). The acute medical care costs of fall-related injuries among the U.S. older adults. Injury, 36(11), 1316-1322.

Rushford, N., Murphy, B.M., Worcester, M.U., Goble, A.J., Higgins, R.O., Le Grande, M.R., et al. (2007). Recall of information received in hospital by female cardiac patients. European Journal of Cardiovascular Prevention and Rehabilitation, 14(3), 463-469.

Saez, T., Suarez, C., Blanco, F., \& Gabriel, R. (1998). Epidemiology of cardiovascular diseases in the Spanish elderly population. Revista Española de Cardiologia, 51, 864-873.

Shaw, B.A., \& Spokane, L. (2008). Examining the association between education-level and physical activity changes during early old age. Journal of Aging and Health, 20, 767-787.

Sheppard, L., Senior, J., Park, C.H., Mockenhaupt, R., \& Chodzko-Zajko, W. (2003). Strategic priorities for increasing physical activity among adults age 50 and older: The National Blueprint Consensus Conference summary report. Journal of Aging and Physical Activity, 11(3), 286-292.
Shephard, R.J. (2000). For debate: Medical clearance: A possible inhibitor of physical activity in the elderly? Trends in Canadian thought. Science and Sports, 15(4), 207-211.

Singh-Manoux, A., Adler, N.E., \& Marmot, M.G. (2003). Subjective social status: its determinants and its association with measures of ill-health in the Whitehall II study. Social Science \& Medicine, 56, 1321-1333.

Stephens, T., \& Craig, C.L. (1990). The well-being of Canadians: Highlights of the 1988 Campbell's Soup survey. Ottawa, Ontario, Canada: Canadian Fitness and Lifestyle Research Institute.

Taylor, A.H., Cable, N.T., Faulkner, G., Hillsdon, M., Narici, M., \& Van Der Bij, A.K. (2004). Physical activity and older adults: a review of health benefits and the effectiveness of interventions. Journal of Sport Science, 22(8), 703-725.

Umstattd, M.R., Wilcox, S., Saunders, R., Watkins, K., \& Dowda, M. (2008). Self-regulation and physical activity: the relationship in older adults. American Journal of Health Behavior, 32(2), 115-124.

Vaqué-Rafart, J., \& San José-Laporte, A. (2002). Envejecimiento: problemas que plantea y soluciones adoptadas [Aging: problems and adopted solutions]. In G. Piédrola Gil (Ed.), Medicina Preventiva y salud pública [Preventive Medicine and Public Heath] (pp. 867-886). Barcelona, Spain: Masson.

World Health Organization. (2004). Global Strategy on Diet, Physical Activity and Health. Geneva, Switzerland: WHO.

Zhao, G., Ford, E.S., Li, C., \& Balluz, L.S. (2011). Physical activity in U.S. older adults with diabetes mellitus: Prevalence and correlates of meeting physical activity recommendations. Journal of American Geriatric Society, 59(1), 132-137. 